\title{
Types of DNA methylation status of the interspersed repetitive sequences for LINE-1, Alu, HERV-E and HERV-K in the neutrophils from systemic lupus erythematosus patients and healthy controls
}

\author{
Patadon Sukapan ${ }^{1}$, Paramate Promnarate ${ }^{2}$, Yingyos Avihingsanon ${ }^{3}$, Apiwat Mutirangura ${ }^{4}$ \\ and Nattiya Hirankarn ${ }^{1}$
}

Changes of the DNA methylation at the interspersed repetitive sequences can occur in various conditions including cancer as well as autoimmune diseases. We previously reported the hypomethylation of LINE-1 and HERV-E in the lymphocytes of systemic lupus erythematosus (SLE) patients. As neutrophils are another important cell type contributing to SLE pathogenesis, in this study, we evaluated the methylation levels and patterns for LINE-1, ALU, HERV-E and HERV-K in the neutrophils from SLE patients compared with the healthy controls. We observed that the methylation levels, especially for LINE-1, in the neutrophils from SLE patients were significantly lower than the healthy controls $(P$-value $<0.0001)$. Interestingly, this hypomethylation was not correlated with the activity of the disease. Furthermore, the methylation levels and patterns for Alu, HERV-E and HERV-K in the neutrophils from the SLE patients were not significantly different from the healthy controls. In addition, we further investigated whether there were any correlations between the intragenic LINE-1 and differential expressions of the neutrophils from the SLE patients using public arrays data. The upregulated genes in the neutrophils from the SLE patients were significantly associated with the genes containing LINE-1s compared with the healthy controls ( $P$-value GSE27427 $=7.74 \times 10^{-3}$; odds ratio $\left.(O R)=1.28\right)$. Interestingly, this association was mainly found among genes with antisense LINE-1s ( $P$-value GSE27427 $=6.22 \times 10^{-3} ; \mathrm{OR}=1.38$ ). Bioinformatics data suggest that LINE-1 hypomethylation may affect expression of the genes that may contribute to the pathogenesis of SLE. However, additional functional studies of these proposed genes are warranted to prove this hypothesis. Journal of Human Genetics (2014) 59, 178-188; doi:10.1038/jhg.2013.140; published online 16 January 2014

Keywords: ALU; DNA methylation; HERV-E; HERV-K; LINE-1; neutrophil; systemic lupus erythematosus

\section{INTRODUCTION}

Several previous studies have demonstrated the importance of epigenetics in human pathologies such as inflammatory response and malignancies, especially the dysregulation of the DNA methylation processes. In systemic lupus erythematosus (SLE) patients, many have reported the presence of DNA hypomethylation in various cell types such as leukocytes, peripheral blood mononuclear cells, $\mathrm{T}$ cells and $\mathrm{CD} 4{ }^{+}$T cells. ${ }^{1-4}$ As for the location of DNA hypomethylation, the genome-wide methylation array was used to identify the methylation profile of the $\mathrm{CpG}$ islands in the promoters of several genes in the $\mathrm{CD} 4{ }^{+} \mathrm{T}$ cells of SLE patients., ${ }^{5,6}$ In addition, adoptive transfer of $\mathrm{CD}_{4}{ }^{+} \mathrm{T}$ cells with hypomethylated DNA can induce SLE- like autoimmune disease in nonsusceptible mice. ${ }^{7}$ These results indicated that DNA methylation is a major etiology for SLE. However, methylation occurs not only in the gene promoter but also at the interspersed repetitive sequences (IRSs) that are rich in CpG sequences and make up as much as $45 \%$ of the human genome. The IRSs can be divided into two major groups based on its location. DNA transposons comprise $2.8 \%$ of the human genome, whereas $42.2 \%$ of the genome are retrotransposons. The retrotransposon can be further classified according to its structure based on the presence or absence of the long terminal repeats (LTRs) into two groups: nonLTR retroelements and LTR retroelements. The majority of high copies of non-LTR retroelements are long interspersed nuclear

${ }^{1}$ Center of Excellence in Immunology and Immune Mediated Diseases, Department of Microbiology, Faculty of Medicine, Chulalongkorn University, Bangkok, Thailand; ${ }^{2}$ Medical Sciences Program, Faculty of Medicine, Chulalongkorn University, Bangkok, Thailand; ${ }^{3}$ Center of Excellence in Immunology and Immune Mediated Diseases, Department of Medicine, Faculty of Medicine, Chulalongkorn University, Bangkok, Thailand and ${ }^{4}$ Center of Excellence in Molecular Genetics of Cancer and Human Diseases, Department of Anatomy, Faculty of Medicine, Chulalongkorn University, Bangkok, Thailand

Correspondence: Professor N Hirankarn, Center of Excellence in Immunology and Immune-Mediated Diseases, Department of Microbiology, Faculty of Medicine, Chulalongkorn University, Bangkok 10330, Thailand.

E-mail: Nattiya.H@chula.ac.th

Received 26 November 2013; revised 20 December 2013; accepted 21 December 2013; published online 16 January 2014 
elements (LINEs) that constitute $16.9 \%$ of the human genome. Short interspersed nuclear elements such as Alu constitute $10.6 \%$ of the human genome. Meanwhile, the majority of high copies of LTR retroelements in the human genome are the human endogenous retroviruses (HERVs) that constitute $8.3 \%$ of the human genome. ${ }^{8}$

Hypomethylation of LINE-1, ALU and HERV have been found in cancer, ${ }^{9}$ embryogenesis, ${ }^{10}$ aging, ${ }^{11}$ congenital malformation, ${ }^{12}$ exposure to certain environment, ${ }^{13}$ nutrition deficiency ${ }^{14}$ and autoimmune diseases. It was hypothesized that LINE-1 and other IRS hypomethylation regulate the adjacent cellular genes and contribute to the pathogenesis of the disease. ${ }^{15}$ We have previously reported that LINE-1 hypomethylation is found in $\mathrm{CD}^{+} \mathrm{T}$ lymphocytes, $\mathrm{CD}^{+} \mathrm{T}$ lymphocytes and $\mathrm{B}$ lymphocytes of SLE patients. ${ }^{16}$ Other groups have reported the presence of LINE-1 hypomethylation in synovial fibroblasts among rheumatoid arthritis patients. ${ }^{17}$ In addition, there are evidences that transcripts from LINE-1 and specific HERV such as HERV-E and HERV-K (for gag expression) are upregulated in lupus and rheumatoid arthritis patients, respectively. ${ }^{18-20}$ We also recently reported that there was hypomethylation of HERV-E in CD4 T cells from active lupus patients. $^{21}$

Aside from the peripheral blood mononuclear cells and lymphocytes, another important cell that may contribute to the pathogenesis of SLE is the neutrophils. Neutrophils are the most abundant immune cells and make up $\sim 40-60 \%$ of the white blood cell population. Several studies have reported that irregular neutrophil function was associated with SLE. For example, there were increases in the percentage of apoptotic neutrophil from patients with SLE, and SLE neutrophil apoptosis positively correlated with disease activity and may contribute to autoantigen excess. The increased apoptosis and NETosis in SLE neutrophil might be important in the promotion of autoimmunity and the development of organ damage in SLE. ${ }^{22,23}$ Previous studies have reported the presence of global DNA methylation changes in the white blood cells from SLE patients. ${ }^{1}$ However, there are limited data on DNA methylation in neutrophils from SLE patients. As methylation pattern is specific for a cell type, it is not surprising that some recent studies have shown that methylation profile from myeloid cells was different from lymphoid cells. ${ }^{24,25}$ It is possible that the methylation changes in the neutrophils may be one of the main components contributing to the pathogenesis of SLE.

As a result of this, we assessed the DNA methylation levels and patterns for LINE-1, Alu and HERV in the neutrophils from healthy controls and SLE patients by using the combined bisulfite restriction analysis (COBRA) method.

\section{MATERIALS AND METHODS}

\section{Subjects}

Twenty female patients diagnosed with SLE based on the American College of Rheumatology (ACR) criteria were recruited from the King Chulalongkorn Memorial Hospital. All patients with SLE were classified according to the severity of the disease by the Systemic Lupus Erythematosus Disease Activity Index 2000 (SLEDAI-2K). Inactive disease was defined as SLEDAI-2K score of $\leqslant 6$ (10 inactive SLE patients), whereas active disease was defined as having SLEDAI-2K score of $>6$ (10 active SLE patients) ${ }^{26}$ The demographic data of the patients with SLE are shown in Table 1. Twenty age-matched healthy female volunteers with no history of any autoimmune disease and cancer served as the healthy controls. Informed consent was obtained from each subject before entering the study. The study was approved by the Institutional Review Board of the Faculty of Medicine, Chulalongkorn University, Bangkok, Thailand.

\section{Cell isolation}

The polymorphonuclear granulocytes (PMNs) or neutrophils were isolated from heparinized venous blood by gradient centrifugation. In brief, the collected heparinized blood was diluted in RPMI by a ratio of 1:1. The diluted blood was carefully layered on top of the polymorphprep (AXIS-SHIELDPoC.com, Oslo, Norway). The PMN fraction obtained from the gradient centrifugation was collected and washed once with RPMI. The red blood cells were removed from the PMN fraction by using hypotonic lysis buffer. PMNs were collected, spun and resuspended in RPMI. A hemacytometer was used to count the PMNs. The purity of PMNs was confirmed by cytospin method and evaluated by flow cytometry. PMNs were stored at $-80^{\circ} \mathrm{C}$ until further analysis.

Table 1 Clinical data of the patients and their medications

\begin{tabular}{|c|c|c|c|c|c|}
\hline Patient & Group & Age & Sex & $S L E D A I-2 K$ & Medications \\
\hline 1 & Inactive & 18 & $\mathrm{~F}$ & 5 & Oral Prednisolone 5 mg day $^{-1}$, Immuran 50 mg day $^{-1}$ \\
\hline 2 & Active & 20 & $\mathrm{~F}$ & 10 & Oral Prednisolone $5 \mathrm{mg} \mathrm{day}^{-1}$, Cellcept $2.0 \mathrm{~g} \mathrm{day}^{-1}$, Immuran $50 \mathrm{mg} \mathrm{day}^{-1}$ \\
\hline 3 & Inactive & 17 & $\mathrm{~F}$ & 0 & None \\
\hline 4 & Active & 24 & $\mathrm{~F}$ & 16 & Oral Prednisolone $10 \mathrm{mg} \mathrm{day}^{-1}$, Cellcept 2.0 g day $^{-1}$ \\
\hline 5 & Inactive & 37 & $\mathrm{~F}$ & 0 & Oral Prednisolone $2.5 \mathrm{mg}$ day $^{-1}$, Cellcept $0.5 \mathrm{~g}_{\text {day }}{ }^{-1}$ \\
\hline 6 & Active & 39 & $\mathrm{~F}$ & 12 & Oral Prednisolone $20 \mathrm{mg}$ day $^{-1}$ \\
\hline 7 & Inactive & 38 & $\mathrm{~F}$ & 5 & Oral Prednisolone $10 \mathrm{mg}$ day $^{-1}$ \\
\hline 8 & Inactive & 29 & $\mathrm{~F}$ & 4 & Oral Prednisolone $5 \mathrm{mg}$ day $^{-1}$, Cellcept 2.0 g day $^{-1}$ \\
\hline 9 & Inactive & 39 & $\mathrm{~F}$ & 4 & Oral Prednisolone $2.5 \mathrm{mg} \mathrm{day}^{-1}$ \\
\hline 10 & Inactive & 49 & $\mathrm{~F}$ & 6 & Oral Prednisolone $2.5 \mathrm{mg}$ day $^{-1}$, Immuran $25 \mathrm{mg}$ day $^{-1}$ \\
\hline 11 & Active & 29 & $\mathrm{~F}$ & 14 & Oral Prednisolone 5 mg day $^{-1}$, Immuran $_{100}$ mg day $^{-1}$ \\
\hline 12 & Active & 21 & $\mathrm{~F}$ & 14 & Oral Prednisolone $40 \mathrm{mg} \mathrm{day}^{-1}$ \\
\hline 13 & Active & 28 & $\mathrm{~F}$ & 10 & Oral Prednisolone 10 mg day $^{-1}$, Immuran 75 mg day $^{-1}$ \\
\hline 14 & Inactive & 25 & $\mathrm{~F}$ & 5 & Oral Prednisolone $5 \mathrm{mg}$ day $^{-1}$ \\
\hline 15 & Active & 40 & $\mathrm{~F}$ & 16 & Oral Prednisolone $15 \mathrm{mg} \mathrm{day}^{-1}$, Endoxan $500 \mathrm{mg} \mathrm{day}^{-1}$, Immuran $^{2} 0 \mathrm{mg} \mathrm{day}^{-1}$ \\
\hline 16 & Inactive & 30 & $\mathrm{~F}$ & 4 & Oral Prednisolone $2.5 \mathrm{mg}$ day $^{-1}$, Immuran $^{2} 0 \mathrm{mg} \mathrm{day}^{-1}$ \\
\hline 17 & Active & 46 & $\mathrm{~F}$ & 10 & Oral Prednisolone $20 \mathrm{mg}$ day $^{-1}$ \\
\hline 18 & Inactive & 31 & $\mathrm{~F}$ & 2 & None \\
\hline 19 & Active & 19 & $\mathrm{~F}$ & 10 & Oral Prednisolone 15 mg day ${ }^{-1}$ \\
\hline 20 & Active & 29 & $\mathrm{~F}$ & 16 & Oral Prednisolone $2.5 \mathrm{mg} \mathrm{day}^{-1}$ \\
\hline
\end{tabular}

Abbreviations: F, female; SLEDAI-2K, Systemic Lupus Erythematosus Disease Activity Index 2000. 


\section{Cell lines}

For the interassay variation, six carcinoma and lymphoma cell lines were used to normalize the assays: cervical cancer (HeLa and CaSki), hepatocellular carcinoma (HepG2) and leukemia (K-562, Daudi and Jurkat). DNA templates from Hela, Daudi and Jurkat were used as controls for the interassay variation for all LINE-1, Alu and HERV-E experiments. DNA templates from K562, HepG2 and CaSki were used as controls for interassay variation for all HERV$\mathrm{K}$ experiments. The methylation levels for each cell line were standardized and subsequently used for all experiments as the controls. All cell lines were cultured in Dulbecco's modified Eagle's medium or RPMI-1640 (Gibco BRL, Life Technologies, Pairly, UK), supplemented with $10 \%$ heat-inactivated fetal bovine serum (Sigma, St Louis, MO, USA) and incubated at $37^{\circ} \mathrm{C}$ in $5 \% \mathrm{CO}_{2}$.

\section{DNA preparation for COBRA}

DNA was isolated from collected PMNs using a salting out method. ${ }^{27}$ Bisulfite conversion of the DNA was performed using the EZ DNA methylation Kit (Zymo Research, Orange, CA, USA) according to the manufacturer's protocol.

\section{Detection of COBRALINE-1 and COBRAAlu by using the COBRA technique}

Methylation for LINE-1 and Alu were detected via the COBRALINE-1 and COBRAAlu, respectively. ${ }^{28,29}$ These techniques can detect methylated levels of thousands of CpG loci by using a set of conserved primers for each IRS. As these methods were designed to detect two $\mathrm{CpG}$ dinucleotide sites, hence the methylated patterns were also ascertained as shown in Figure 1.

As described previously, bisulfited DNA was amplified by using primers with the following sequences: LINE-1 (GenBank: M80343) forward 5'-ccgtaaggggtta gggagtttt-3' and LINE-1 reverse $5^{\prime}-(\mathrm{a} / \mathrm{g}) \operatorname{taa} a \operatorname{accctcc}(\mathrm{a} / \mathrm{g})$ aaccaaatataaa- $3^{\prime}$; Alu forward $5^{\prime}-\mathrm{gg}(\mathrm{t} / \mathrm{c}) \mathrm{g}(\mathrm{c} / \mathrm{t}) \mathrm{ggtggttta}(\mathrm{c} / \mathrm{t}) \mathrm{gtttgtaa}-3^{\prime}$ and Alu reverse $5^{\prime}$-caccatattaac caaactaatcccga- $3^{\prime}$. The sequences for the primers for Alu were based on the nucleotides of the AluSx subfamily sequence. ${ }^{11}$ The PCR product for COBRALINE-1 was obtained from using the following cycle conditions: initial denaturation at $95^{\circ} \mathrm{C}$ for $15 \mathrm{~min}$ followed by 35 cycles of denaturation at $95^{\circ} \mathrm{C}$ for another $1 \mathrm{~min}$, annealing at $50^{\circ} \mathrm{C}$ for $1 \mathrm{~min}$, extension at $72^{\circ} \mathrm{C}$ for $1 \mathrm{~min}$ and ending with the final extension at $72{ }^{\circ} \mathrm{C}$ for $7 \mathrm{~min}$. The PCR product for COBRAAlu was performed by using the following cycle conditions: initial denaturation at $95^{\circ} \mathrm{C}$ for $15 \mathrm{~min}$ followed by 45 cycles of denaturation at $95^{\circ} \mathrm{C}$ for another $45 \mathrm{~s}$, annealing at $63^{\circ} \mathrm{C}$ for $45 \mathrm{~s}$, extension at $72^{\circ} \mathrm{C}$ for $45 \mathrm{~s}$ and ending with the final extension at $72{ }^{\circ} \mathrm{C}$ for
7 min. After amplification, the PCR products for LINE-1 (160 bp in length) were digested with two units of TaqI (Fermentas International, Burlington, ON, Canada) and two units of TasI (Fermentas International) restriction enzymes. The PCR products for Alu (133 bp in length) were digested with two units of TaqI (Fermentas International) restriction enzyme. Each digestion reaction was incubated overnight at $65^{\circ} \mathrm{C}$. The DNA fragments were later separated on $8 \%$ polyacrylamide gels. After that, the gel was stained with SYBR green nucleic-acid stain (Invitrogen, Carlsbad, CA, USA). The intensity of the DNA fragments was measured with Phosphoimager using ImageQuant software (Molecular Dynamics, GE Healthcare, Slough, UK). For the normalization of the interassay variation between each experiment, we used the DNA templates from HeLa, Jurkat and Daudicell cell lines as the controls for COBRALINE-1 and COBRAAlu. ${ }^{9}$ The methylation levels for each cell line were standardized and subsequently used for all experiments as the controls.

\section{Analysis for LINE-1 and Alu methylation patterns}

COBRALINE-1 and COBRAAlu results were categorized into four groups based on the status of the methylation at the two $\mathrm{CpG}$ dinucleotides from the $5^{\prime}$ to $3^{\prime}$ of LINE-1 and Alu sequences: (1) hypermethylation at both CpGs (mCmC), (2) hypomethylation at $\mathrm{CpGs}(\mathrm{uCuC}),(3)$ partial methylation of the $\mathrm{mCuC}$ and (4) partial methylation of the $\mathrm{uCmC}$ (Figure 1). The LINE-1 and Alu methylation levels were calculated for each group based on the intensity of COBRA-digested LINE-1 and Alu products. Phosphorimager and the ImageQuant Software (Molecular Dynamics, GE Healthcare) were used to quantify the intensities of the COBRALINE-1 and Alu bands. The number of CpG dinucleotides of each band was normalized by dividing the band intensity by the number of double-stranded bp of the DNA sequence as follows: \%160/ $160=\mathrm{A} ; \% 98 / 94=\mathrm{B} ; \% 80 / 79=\mathrm{C} ;$ and $\% 62 / 62=\mathrm{D}$. Then, LINE-1 methylation levels were calculated with the following formula: LINE-1 methylation level percentage $(\% \mathrm{mC})=100 \times(\mathrm{C}+\mathrm{A}) /(\mathrm{C}+\mathrm{A}+\mathrm{A}+\mathrm{B}+\mathrm{D})$; percentage of $\mathrm{mCuC}$ loci $(\% \mathrm{mCuC})=100 \times(\mathrm{A}) /((\mathrm{C}-\mathrm{D}+\mathrm{B}) / 2)+\mathrm{A}+\mathrm{D})$; percentage of $\mathrm{uCmC}$ loci $(\% \mathrm{uCmC})=100 \times(\mathrm{D}-\mathrm{B}) /((\mathrm{CD}+\mathrm{B}) / 2)+\mathrm{A}+\mathrm{D}$; percentage of $\mathrm{uCuC}$ loci $(\% \mathrm{uCuC})=100 \times \mathrm{B} /(((\mathrm{C}-\mathrm{D}+\mathrm{B}) / 2)+\mathrm{A}+\mathrm{D})$; and percentage of $\mathrm{mCmC}$ loci $(\% \mathrm{mCmC})=100 \times((\mathrm{C}-\mathrm{D}+\mathrm{B}) / 2) /(((\mathrm{C}-\mathrm{D}+\mathrm{B}) / 2)+\mathrm{D}+$ A). ${ }^{28,30}$ The number of $\mathrm{CpG}$ dinucleotides of COBRAAlu was normalized similarly to LINE-1 as follows: $\% 133 / 133=\mathrm{A} ; \% 58 / 58=\mathrm{B} ; \% 75 / 75=\mathrm{C} ; \% 90 /$ $90=\mathrm{D} ; \% 43 / 43=\mathrm{E} ;$ and $\% 32 / 32=\mathrm{F}$. Alu methylation levels were calculated with the following formula: Alu methylation level percentage $(\% \mathrm{mC})=100 \times(\mathrm{E}+\mathrm{B}) /(2 \mathrm{~A}+\mathrm{E}+\mathrm{B}+\mathrm{C}+\mathrm{D})$; percentage of $\mathrm{mCmC}$ loci a COBRALINE-1 methylation profile

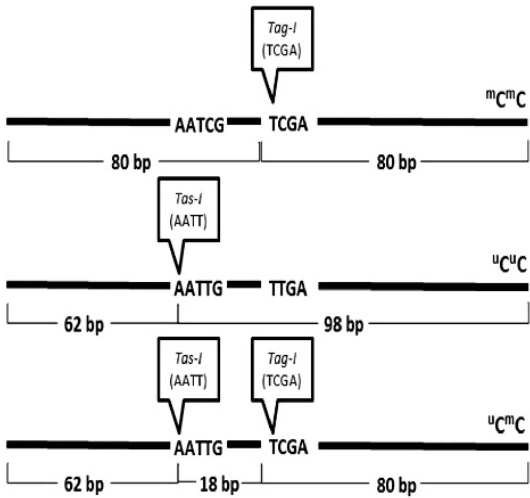

\section{b COBRAAlu methylation profile}

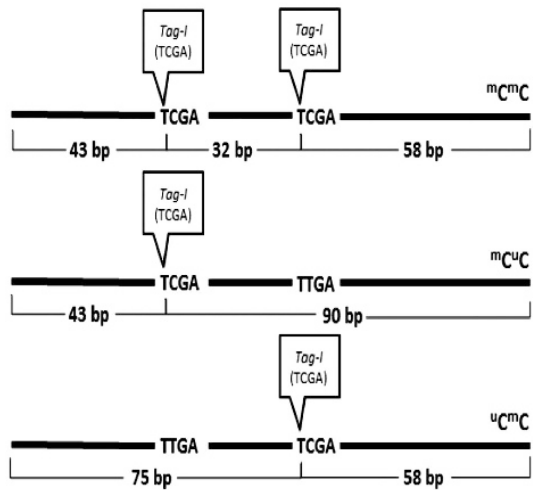

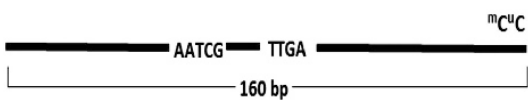

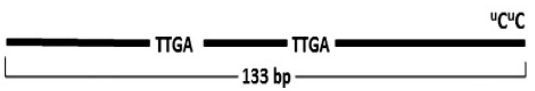

Figure 1 Combined bisulfite restriction analysis (COBRA) technique for LINE-1 and Alu. (a) LINE-1 and (b) Alu amplicon sizes are 160,133 and 126 bp, respectively. The products of Line- 1 and Alu were digested by restriction enzymes (Taql and Tasl). The LINE-1 amplicons were 160, 98,80 and 62 bp. Alu amplicons were $133,90,75,58$ and $43 \mathrm{bp}$. The methylation levels were calculated as a percentage of the intensity of the digested methylation fragment divided by the sum of the undigested and digested products. Marker is low-range DNA ladder. 
$(\% \mathrm{mCmC})=100 \times \mathrm{F} /(\mathrm{A}+\mathrm{C}+\mathrm{D}+\mathrm{F})$; percentage of $\mathrm{uCmC}$ loci $(\% \mathrm{uCmC})$ $=100 \times \mathrm{C} /(\mathrm{A}+\mathrm{C}+\mathrm{D}+\mathrm{F})$; percentage of $\mathrm{mCuC}$ loci $(\% \mathrm{mCuC})=100 \times \mathrm{D} /$ $(\mathrm{A}+\mathrm{C}+\mathrm{D}+\mathrm{F}) ;$ and percentage of $\mathrm{uCuC}$ loci $(\% \mathrm{uCuC})=100 \times \mathrm{A} /$ $(\mathrm{A}+\mathrm{C}+\mathrm{D}+\mathrm{F})^{28,30}$

\section{Detection of COBRAHERV-E and COBRA-HERV-K by using the COBRA technique}

The techniques used to detect the methylation for HERV-E and HERV-K were done by using COBRAHERV-E and COBRAHERV-K, respectively, that have previously been validated to be accurate and reliable techniques. ${ }^{21}$ These techniques are similar to COBRALINE- 1 and COBRAAlu but are mainly used to detect the overall methylation level instead of the pattern for partial or complete hypomethylation. Briefly, bisulfited DNAs were amplified by using primers with the following sequences: HERV-E (Genbank: M10976) forward $5^{\prime}$-TTTTGTTAGTTGATGT(A/G)(G/T)GTA-3' and HERV-E reverse $5^{\prime}$-CCCCAAAAAAAAAATTC(C/T)TAACC- $3^{\prime}$; and HERV-K (GenBank: M14123) forward $5^{\prime}$-ATATTAAGGGAATTTAGAGGTTGG- ${ }^{\prime}$, and HERV-K reverse $5^{\prime}$-CCCCTACACACCTATAAATATTTC-3'. The PCR product for COBRAHERV-E was obtained by using the following cycle conditions: initial denaturation at $95^{\circ} \mathrm{C}$ for 5 min followed by 35 cycles of denaturation at $95^{\circ} \mathrm{C}$ for another $1 \mathrm{~min}$, annealing at $58^{\circ} \mathrm{C}$ for $1 \mathrm{~min}$, extension at $72{ }^{\circ} \mathrm{C}$ for $1 \mathrm{~min}$ and ending with the final extension at $72^{\circ} \mathrm{C}$ for $7 \mathrm{~min}$. The PCR product for COBRAHERV-K was performed by using the cycle conditions that are similar to COBRAHERV-E except for the annealing step that is done at $60{ }^{\circ} \mathrm{C}$ for 1 min with the HERV-K primers. After amplification, the PCR products for HERV-E (126 bp in length) and HERV-K (156 bp in length) were digested with two units of TaiI (Fermentas International) restriction enzyme. Each digestion reaction was incubated overnight at $65^{\circ} \mathrm{C}$ and later separated on $8 \%$ nondenaturing polyacrylamide gels. After that, the gel was stained by using the SYBR green nucleic-acid stain (Invitrogen). The intensity of the DNA fragments was measured with Phosphoimager using the ImageQuant software (Molecular Dynamics, GE Healthcare). For the normalization of the interassay variation between each experiment, we used the DNA templates from HeLa, Daudi and Jurkat cell lines as the controls for COBRAHERV-E and K562, whereas for COBRAHERV-K we used HepG2 and CaSki cell lines. The methylation levels for each cell line were standardized and subsequently used for all experiments as the controls.

The methylation levels for both were calculated by using the following equation: ${ }^{21}$

$\%$ Methylation $=$ Intensity of the digested methylated fragment $\times 100$ Intensity of undigested + digested - amplicons

\section{Analysis for CU-DREAM X}

Connection Up- or Down-Regulation Expression Analysis of Microarrays X (CU-DREAM X) program was used to measure the correlation between genes containing LINE-1 and differential expression of the SLE expression array to identify LINE-1-regulated genes that are expressed differently in the neutrophils from SLE patients. The program used is located at http://pioneer.netserv. chula.ac.th/ achatcha/cu-dream/. ${ }^{31,32}$ The gene containing LINE-1 data was entered into the Llbase database (http://l1base.molgen.mpg.de). ${ }^{33}$ The extracted microarray data were available from the Gene Expression Omnibus (GEO) data set (http://www.ncbi.nlm.nih.gov/geo), a public repository that archives and freely distributes microarray data submitted by the scientific community. ${ }^{34,35}$ The correlation between the expressions for the SLE neutrophils' microarray libraries from the GEO data set GSE27427 (GarciaRomo et al. ${ }^{36}$ ) and genes containing LINE-1 data were analyzed. The number of genes in each subset was compared with the genes containing or not containing LINE-1 by using the $\chi^{2}$ test. A $P$-value of $<0.01$ indicated that there was a significant correlation that was specific between the genecontaining LINE-1 and the differential expression array. The odds ratios (ORs) of $>1$ indicated that the intragenic LINE-1-regulated genes in one study were also regulated in another study. When the ORs were $<1$, this indicated that the event of interest (up or down) inhibited the mechanism(s) that altered the gene expression in another experiment. ${ }^{32}$

\section{Functional Classification Analysis by Bioinformatics Tool}

We performed gene functional classification analysis by using the DAVID Bioinformatics tool (http://david.abcc.ncifcrf.gov/home.jsp). ${ }^{37,38} \mathrm{~A}$ list of genes was generated with the EASE (Expression Analysis Systematic Explorer) scores by using the DAVID functional annotation chart. The scores were a modified Fisher's exact $P$-value for each enriched annotated term and calculated for the geometric mean for the EASE scores for those terms involved in this gene group. Minus log transformation was applied to the geometric mean to emphasize the geometric mean as a relative score instead of an absolute $P$-value. For example, an enrichment score of 0.05 is equivalent to 1.3 in the minus log scale. The rankings of the biological significance of the gene groups are based on their overall EASE scores (enrichment score) for all enriched annotated terms. Therefore, a higher enrichment score for a group indicated that the genes were more involved in the pathogenesis for SLE. ${ }^{38}$ Furthermore, the pathway analysis was performed by using the DAVID Bioinformatics tool (http://david.abcc.ncifcrf.gov/home.jsp).

\section{Statistical analyses}

We applied an independent or dependent sample $t$-test (significance twotailed) to compare the methylated levels between the groups. A $P$-value of $<0.05$ was considered to be statistically significant. Pearson's correlation coefficient was used to examine the relationship between two continuous variables. All analyses were performed by using the SPSS software for windows version 15.0 (SPSS, Chicago, IL, USA).

\section{EST database search}

Nucleotides from 1 to 500 of the human transposon L1.2 (GenBank accession no. M80343) were used to search for LINE-1 chimeric transcripts in the human expressed sequence tag (EST) database (GenBank) by using the BLAST (Basic Local Alignment Search Tool) program. To identify the gene exon, the matched ESTs were subsequently analyzed by the BLAST program against the human reference RNA database (GenBank). ESTs with both LINE-1 and gene exon were classified as chimeric ESTs.

\section{RESULTS}

Differences in the DNA methylation levels for LINE-1, Alu and HERV in the neutrophils from the SLE patients versus the healthy controls

From the COBRAAlu, COBRAHERV-E and COBRAHERV-K analyses, there were no significant differences in the methylation levels and patterns in the neutrophils from the patients with SLE $(n=20)$ and healthy controls $(n=20$; Figures $2 \mathrm{~b}-\mathrm{d})$. However, significant differences were detected in LINE-1 methylation levels and patterns in the neutrophils from the patients with SLE $(n=20)$ when compared with the healthy controls $(n=20)$ as shown in Figure 2a. When each pattern was analyzed, the number of hypermethylated loci at both positions (mCmC) of LINE-1 from the neutrophils of SLE patients $(n=20)$ was significantly lower than the healthy controls $(n=20$; $P<0.0001)$. Percent hypermethylation in SLE neutrophils compared with methylation in normal neutrophils is $27.5 \%$ and $32 \%$, respectively. Moreover, the number of hypomethylated loci at both positions $(\mathrm{uCuC})$ for LINE-1 from the neutrophils from the SLE patients $(n=20)$ was significantly higher than the healthy controls $(n=20$; $P=0.0028$ ). Percent hypomethylation in SLE neutrophils compared with methylation in normal neutrophils is $31.6 \%$ and $29.2 \%$, respectively. The percentage for the partial position of $\mathrm{mCuC}$ pattern for LINE-1 was significantly higher in the neutrophils from the patients with SLE $(n=20)$ than the healthy controls $(n=20$; $P<0.0001$ ). Percent $\mathrm{mCuC}$ methylation in SLE neutrophils compared with methylation in normal neutrophils is $22 \%$ and 19.3 , respectively. However, there were no significant differences in the percentages for $\mathrm{uCmC}$ pattern for LINE- 1 between the patients with SLE $(n=20)$ and the healthy controls $(n=20 ; P=0.6368)$. 
a

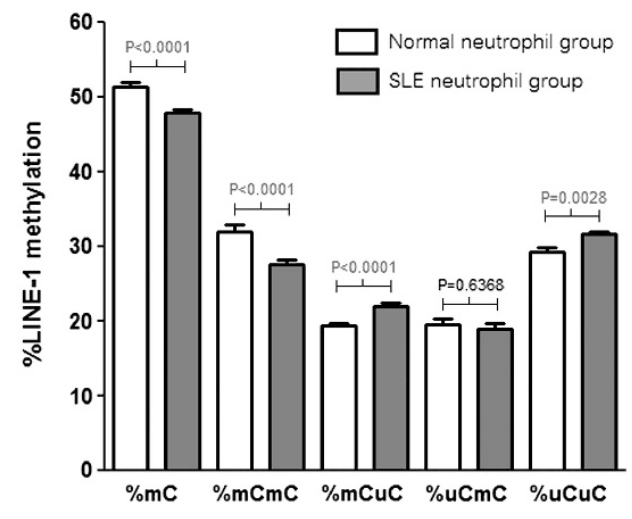

C COBRAHERV-E methylation profile

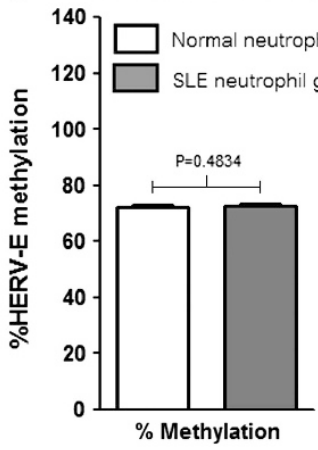

b

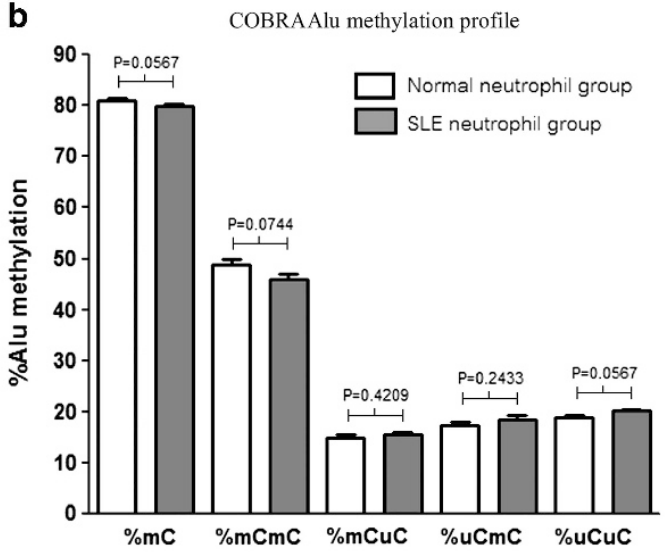

d COBRAHERV-K methylation profile

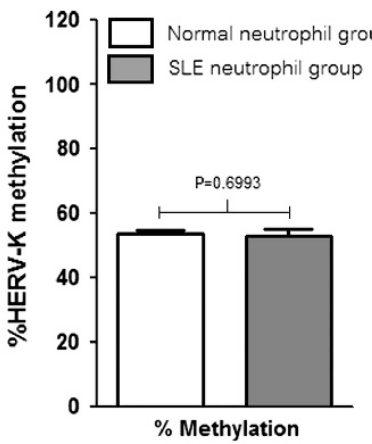

Figure 2 Each pattern of (a) LINE-1, (b) Alu, (c) HERV-E and (d) HERV-K methylation levels in systemic lupus erythematosus (SLE) neutrophils compared with normal neutrophils is shown as mean \pm s.e.m. $P$-value calculated by unpaired $t$-test two-tailed analysis.

LINE-1 methylation is not associated with the activity of the disease for SLE

We analyzed the association between each LINE-1 methylation pattern and level with the SLEDAI score. There were no significant correlations between each pattern of LINE-1 methylation level and the SLEDAI score (Figure 3). The DNA methylation levels for LINE-1 in the neutrophils from the patients with inactive and active SLE were compared with the healthy controls. The SLE patients were classified according to the severity of the disease and divided into two groups based on their SLEDAI-2K scores: active and inactive groups. We analyzed the association of LINE-1 methylation pattern and disease activity in 10 inactive SLE patients, 10 active SLE patients and 20 healthy controls. The overall pattern for LINE-1 methylation level was significantly not different between the inactive and active SLE groups (Figure 4)

\section{The correlation between intragenic LINE-1 and differential} expressions in the neutrophils from SLE patients based on the expression array

Several studies have shown that the intragenic LINE-1 (gene containing LINE-1) hypomethylation in cancer cells can regulate the host gene expressions in cis. ${ }^{15}$ Therefore, we would like to indirectly test this hypothesis for SLE by analyzing whether intragenic LINE-1 hypomethylation is correlated with the gene expression in the neutrophils from the SLE patients. Genes processing LINE-1 were determined by L1base and listed by Aporntewan et al. ${ }^{31}$ The CUDREAMX program was used to evaluate the association of the genes containing intragenic LINE-1 and the level of the gene expression as described previously. ${ }^{31}$ Genes containing LINE-1 were classified into four groups based on the presence of intragenic LINE-1 into: (1) genes containing L1s 1454 genes, (2) genes with sense L1s 336 genes, (3) genes with antisense L1s 832 genes and (4) genes with both sense and antisense L1s 286 genes. The $\chi^{2}$ test was used to evaluate the association of the genes containing intragenic LINE-1 with the gene expression of the neutrophils from the SLE patients by using an intersection between the expression microarray data available from GEO, GSE27427 and gene-containing LINE-1 (4 groups) (Table $2 \mathrm{a}-\mathrm{d}$ ). The upregulated genes were significantly associated with the genes containing LINE-1 in the neutrophils from the SLE patients compared with the healthy controls $(P$-value GSE27427 $=$ $\left.7.74 \times 10^{-3} ; \mathrm{OR}=1.28\right)$. Interestingly, the genes with antisense LINE-1s were significantly more prevalent in the upregulated genes in the neutrophils from the SLE patients than the healthy controls $\left(P\right.$-value GSE27427 $=6.22 \times 10^{-3} ; \mathrm{OR}=1.38$; Table 3$)$.

Bioinformatics analysis of the up- or down-regulated genes containing LINE-1s that are involved in the biological processes for cell apoptosis and induction of programmed cell death

To identify functional networks, the genes with intragenic LINE-1 that were associated with the gene expression of the neutrophils from the SLE patients were analyzed by performing the gene category $P$-value analysis using the online available DAVID bioinformatics resources. Any group with the functional annotation chart of $P$-value $\leqslant 0.05$ was analyzed. In summary, the upregulated genes containing LINE-1s are shown to be involved in the biological processes for cell apoptosis and induction of programmed cell death. The downregulated genes containing LINE-1s were found to be responsible for innate immune 
a

a LINE-1 methylation pattern and SLEDAI score in neutrophil

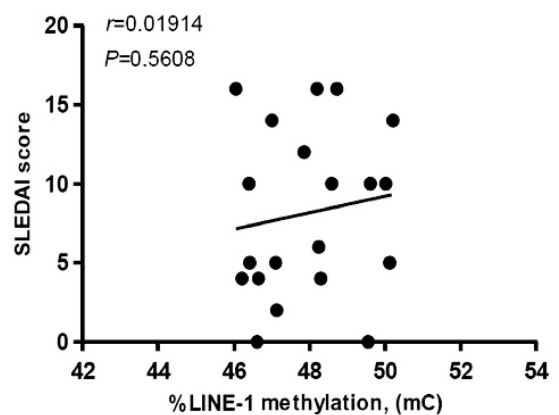

b

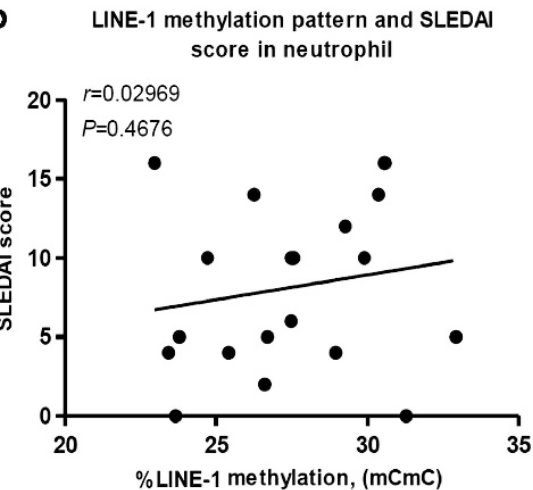

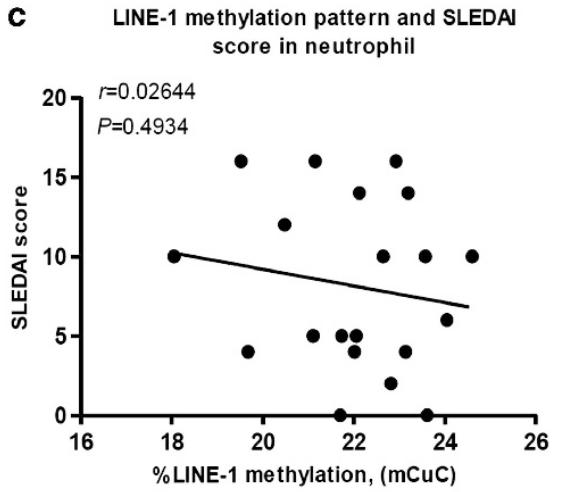
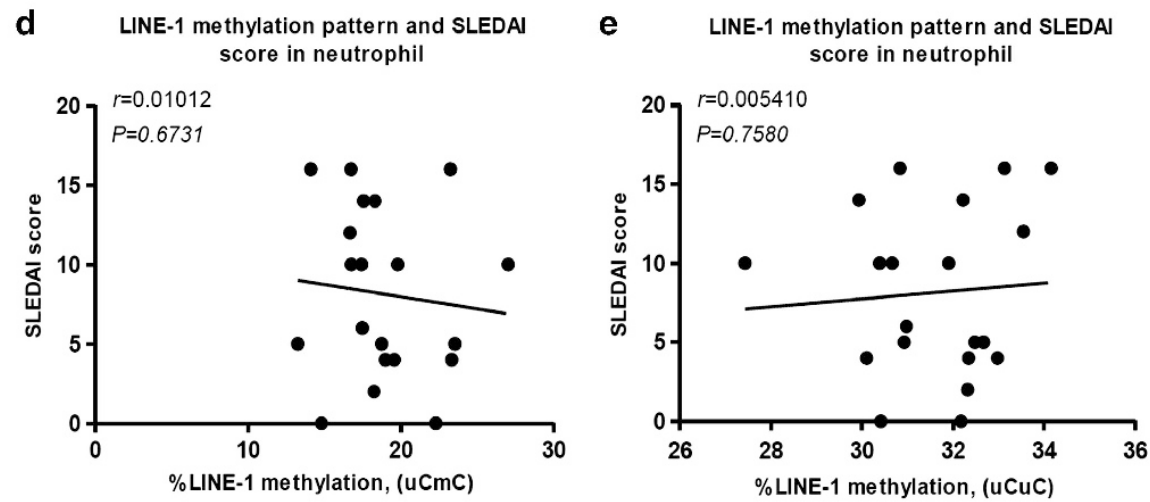

Figure 3 Correlation between each pattern of LINE-1 methylation levels with Systemic Lupus Erythematosus Disease Activity Index (SLEDAI) score in neutrophils of systemic lupus erythematosus (SLE) patients is shown. (a) $\mathrm{mC}$, (b) $\mathrm{mCmC}$, (c) $\mathrm{mCuC}$, (d) $\mathrm{uCmC}$ and (e) uCuC. Each dot represents an individual patient. $P$-value calculated by Pearson's correlation coefficient test.

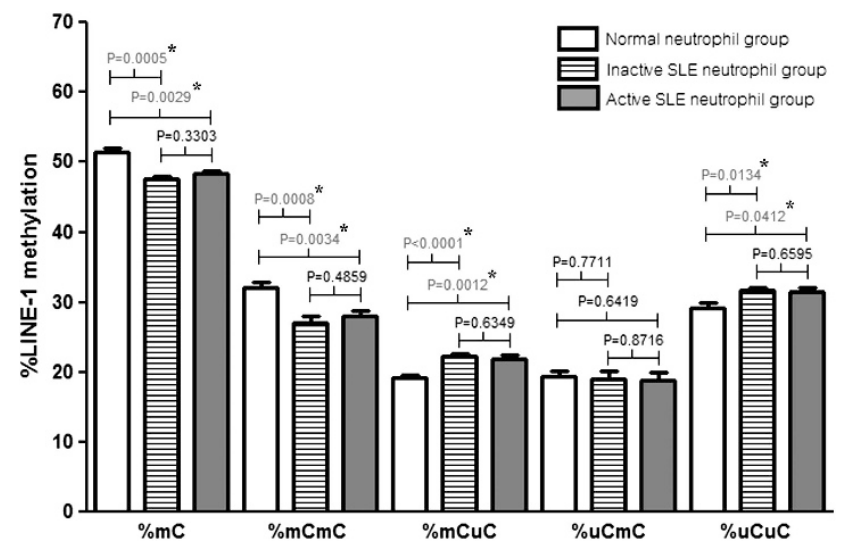

Figure 4 Each pattern of LINE-1 methylation levels in different SLE disease activity is shown as mean \pm s.e.m. $P$-value calculated by unpaired $t$-test two-tailed analysis.

response, lymphocyte-mediated immunity and leukocyte-mediated immunity (Table 4).

\section{EST search for LINE-1 chimeric transcript}

To explore more solid evidence that the genes containing LINE-1 may have a unique LINE-1 chimeric expression, we investigated the LINE-1 chimeric transcripts in the human EST database (GenBank) by using the BLAST program. ESTs with both LINE-1 and gene exon were classified as chimeric ESTs. In Supplementary Tables 1 and 2, 104 genes and their biological functions were identified as the putative
LINE-1 chimeric ESTs from various cancer cells. Out of 104 genes, 9 genes were differentially expressed in the neutrophils from the SLE patients, namely: C12orf4, RABGAP1L, SCAMP1, SSBP2, DCTN4, EPHB1, SLCO1A2, ARHGAP25 and COL24A1. LINE-1 orientation, the gene expression of the SLE neutrophils and their functions are summarized in Table 5.

\section{DISCUSSION}

Our experiments showed that methylation levels and patterns for LINE-1 were significantly lower $(\mathrm{mC}$ and $\mathrm{mCmC}$ ) in the neutrophils from the SLE patients compared with the healthy controls. These hypomethylated results in the neutrophils are consistent with the reports from previous studies conducted in $\mathrm{CD} 4{ }^{+} \mathrm{T}$ lymphocytes, CD8 ${ }^{+} \mathrm{T}$ lymphocytes and B lymphocytes from SLE patients. ${ }^{16}$ Aside from that, another study conducted in rheumatoid arthritis patients also detected hypomethylated LINE-1 in the synovial fibroblasts. ${ }^{17}$ These methylated levels of LINE-1 may be the key feature of pertinent cells that contribute to the pathogenesis for several autoimmune diseases. The mechanisms contributing to LINE-1 hypomethylation are not known. It is possible that LINE-1 hypomethylation may occur before the active disease or occur as the result of the disease. As neutrophils are not commonly or frequently studied, the effects and impact of the DNA changes remain elusive. Interestingly, we did not observe any significant correlation between the methylation level for LINE-1 and the activity for the disease. Similarly, another recent study conducted in naive CD4 ${ }^{+} \mathrm{T}$ cells from lupus patients also did not see any correlation between hypomethylated interferon-regulated genes and the activity for the disease. ${ }^{6}$ They proposed that the 
Table 2 The $2 \times 2$ table of $\chi^{2}$ test was used to evaluate the intragenic LINE-1 to see whether it can control the expression of the genes in the neutrophils from the SLE patients

(a)

\begin{tabular}{|c|c|c|c|c|}
\hline & \multicolumn{4}{|c|}{ GSE27427 SLE neutrophil } \\
\hline & Down $(\mathrm{P}<0.01)$ & Not down & $U p(\mathrm{P}<0.01)$ & Not up \\
\hline LINE-1 & 67 & 1179 & 137 & 1109 \\
\hline \multirow[t]{5}{*}{ No LINE-1 } & 2284 & 21467 & 2088 & 21663 \\
\hline & $P=0.000000582$ & & $P=0.007743$ & \\
\hline & Odds ratio $=0.53$ & & Odds ratio $=1.28$ & \\
\hline & Lower $95 \% \mathrm{Cl}=0.42$ & & Lower $95 \% \mathrm{Cl}=1.07$ & \\
\hline & Upper $95 \% \mathrm{Cl}=0.69$ & & Upper $95 \% \mathrm{Cl}=1.54$ & \\
\hline
\end{tabular}

(b)

\begin{tabular}{|c|c|c|c|c|}
\hline & & GSE & & \\
\hline & Down $(\mathrm{P}<0.01)$ & Not down & Up $(\mathrm{P}<0.01)$ & Not up \\
\hline LINE-1 & 22 & 261 & 27 & 256 \\
\hline No LINE-1 & 2329 & 22385 & 2198 & 22516 \\
\hline & $P=0.344406$ & & $P=0.703951$ & \\
\hline & Odds ratio $=0.81$ & & Odds ratio $=1.08$ & \\
\hline & Lower $95 \% \mathrm{Cl}=0.52$ & & Lower $95 \% \mathrm{Cl}=0.72$ & \\
\hline & Upper $95 \% \mathrm{Cl}=1.25$ & & Upper $95 \% \mathrm{Cl}=1.61$ & \\
\hline
\end{tabular}

(c)

GSE27427 SLE neutrophil

\begin{tabular}{llll} 
& \multicolumn{1}{c}{ Down $(\mathrm{P}<0.01)$} & Not down & Up $(\mathrm{P}<0.01)$ \\
\hline LINE-1 & 37 & 686 & 85 \\
No LINE-1 & 2314 & 21960 & 2140 \\
& $P=0.0000612$ & & $P=0.006215$ \\
& Odds ratio $=0.51$ & Odds ratio $=1.38$ \\
& Lower $95 \% \mathrm{Cl}=0.37$ & Lower $95 \% \mathrm{Cl}=1.09$ \\
& Upper $95 \% \mathrm{Cl}=0.71$ & Upper $95 \% \mathrm{Cl}=1.74$ \\
\hline
\end{tabular}

(d)

GSE27427 SLE neutrophil

\begin{tabular}{lccr} 
& Down $(\mathrm{P}<0.01)$ & Not down & Up $(\mathrm{P}<0.01)$ \\
\hline LINE-1 & 8 & 232 & 25 \\
No LINE-1 & 2343 & 22414 & 215 \\
& $P=0.001203$ & $P=0.407372$ & 22557 \\
& Odds ratio $=0.33$ & Odds ratio $=1.19$ & \\
& Lower $95 \% \mathrm{Cl}=0.16$ & Lower $95 \% \mathrm{Cl}=0.79$ \\
& Upper $95 \% \mathrm{Cl}=0.67$ & Upper $95 \% \mathrm{Cl}=1.81$ &
\end{tabular}

Abbreviations: $\mathrm{Cl}$, confidence interval; SLE, systemic lupus erythematosus.

Gene-containing LINE-1 was classified into four groups based on its regulatory functions and the presence of intragenic LINE-1 ((a) genes containing L1s 1454 genes, (b) genes with sense L1s 336 genes, (c) genes with antisense L1s 832 genes and (d) genes with both sense and antisense L1s 286 genes). Genes for upregulation were denoted by 'Up', whereas the downregulated genes were denoted as 'Down'; the threshold for the P-value used in the paired $t$-test was set at 0.01 . The genes with or without intragenic LINE-1 were denoted by LINE-1 and No LINE-1, respectively. The $P$-values for $2 \times 2$ tables were obtained from the $\chi^{2}$ distribution.

hypomethylated genes in these naive $\mathrm{CD} 4{ }^{+} \mathrm{T}$ cells epigenetically are primed to produce a more rapid type of interferon response.

It is possible that this hypomethylation of LINE-1 may affect the cellular gene expression and contribute to the pathogenesis for SLE, but this remains to be further explored. In this study, we indirectly explored whether these LINE-1 hypomethylations may have any functional significance by investigating the correlation between the intragenic LINE-1 and the differential expressions in the neutrophils from the SLE patients using the data from the expression array (GSE27427). We hypothesized that the intragenic LINE-1 can control the host genes in SLE. The gene expressions in the neutrophils from the SLE patients were compared with the pattern of intragenic LINE1. When we used the CU-DREAM X technique, we observed a higher prevalence of upregulated genes containing LINE-1s in the 
Table 3 The expression status of the genes containing LINE-1s in the neutrophils from the SLE patients were compared with the healthy controls

\begin{tabular}{|c|c|c|c|c|c|c|c|c|}
\hline & \multicolumn{2}{|c|}{ L1s (1454 genes) } & \multicolumn{2}{|c|}{ L1s (336 genes) } & \multicolumn{2}{|c|}{ L1s (832 genes) } & \multicolumn{2}{|c|}{ antisense L1s (286 genes, } \\
\hline & P-value & $O R$ & P-value & $O R$ & P-value & $O R$ & P-value & $O R$ \\
\hline $\begin{array}{l}\text { GSE27427 SLE neutrophil vs normal neutrophils } \\
\text { upregulation }(P<0.01)\end{array}$ & $7.74 \mathrm{E}-03^{*}$ & 1.28 & 0.7 & 1.08 & $6.22 \mathrm{E}-03^{*}$ & 1.38 & 0.41 & 1.19 \\
\hline $\begin{array}{l}\text { GSE27427 SLE neutrophil vs normal neurophils } \\
\text { downregulation }(P<0.01)\end{array}$ & $5.82 \mathrm{E}-07$ & 0.53 & 0.34 & 0.81 & $6.13 \mathrm{E}-05$ & 0.51 & 0.0012 & 0.33 \\
\hline
\end{tabular}

Abbreviations: OR, odds ratio; SLE, systemic lupus erythematosus.

neutrophils from the SLE patients compared with the healthy controls. $^{31,32}$ We further investigated the upregulated genes and its association with each of LINE-1 genes and interestingly found that only antisense LINE-1s were detected in these upregulated genes containing LINE-1s. Recently, Aporntewan et al. ${ }^{31}$ reported that intragenic LINE-1 (gene containing LINE-1) hypomethylation in cancer cells resulted in the regulation of the host gene expressions for cis. They found that intragenic LINE-1 RNAs repressed the host gene expression via the nuclear RNA-induced silencing complex. ${ }^{31}$ However, in this study, we found that intragenic antisense LINE-1 in the neutrophils from the SLE patients was significantly associated with the gene upregulation. Therefore, it is likely that the effect of hypomethylation for the intragenic antisense LINE-1 in the neutrophils from the SLE patients may behave differently compared with the cancer cells. As a result of this finding, we believe that other factors may also be responsible for the pathogenesis of SLE.

Because of this, we hypothesized that some hypomethylated genes of LINE-1 may have a stronger influence in the expression of those genes in close proximity to LINE-1, especially those genes that are related to the pathogenesis for SLE. Thus, we explored the phenotypic data of the upregulated genes containing LINE-1s by using an online program known as the DAVID Bioinformatics Resources that is freely available in the public domain for analyzing bioinformatics data. We noticed that there were high prevalences of upregulated genes containing LINE-1s that were involved in the biological processes for cells such as the induction of apoptosis and programmed cell death. The functions of these upregulated genes, especially for the cell death processes, may explain the pathogenesis for SLE. The downregulated genes containing LINE-1s were involved with the innate immune response, lymphocyte-mediated immunity and leukocytemediated immunity. From 67 downregulated genes, the significant genes were responsible for the innate immune response, lymphocytemediated immunity and leukocyte-mediated immunity. The dysregulation of the cascade activities or functions of the inhibitors in these systems can result in clinical manifestations for certain types of diseases such as systemic lupus erythematosus or ischemia-reperfusion injury with critical thrombotic and inflammatory complications. ${ }^{39}$

As the upregulated genes in the neutrophils are strongly associated with the genes containing antisense LINE-1, we hypothesized that the hypomethylation of LINE-1s can trigger transcription of unique chimeric transcripts of their neighboring genes, driven by LINE-1 antisense promoter. ${ }^{40,41}$ One example of a unique IRS transcript in SLE is the expression of HERV-E.CD5 in cell sorted B1 lymphocytes. ${ }^{42}$ However, there were no previous reports of such an example for such LINE-1 transcripts in SLE. To search for any evidence that the genes containing LINE-1 may have a unique LINE-1 chimeric expression, we investigated the LINE-1 chimeric transcripts in the human EST database (GenBank) by using the BLAST program. ESTs with both LINE-1 and gene exon were classified as LINE-1 chimeric ESTs. This suggested that LINE-1 could regulate its neighboring gene by providing it an alternative promoter. Out of a total of 104 putative LINE- 1 chimeric ESTs, 9 genes were differentially expressed in the neutrophils from the SLE patients. Most of them have LINE-1 in the antisense direction and were upregulated as expected.

One of them, the RAB GTPase activating protein 1-like protein (RABGAP1L), a putative phosphotyrosine binding domain expressed in megakaryocytes, ${ }^{43}$ was shown to be related with SLE. A study conducted in Korean women showed that the deletion of RABGAP1L was associated with the risk for developing SLE. ${ }^{44}$ Aside from that, some genes may be related with cell migration as seen in SLE patients where there is an accumulation of the neutrophils in the targeted organ. For example, the secretory carrier membrane protein 1 (SCAMP1) is a membrane protein that has a role in exocytosis ${ }^{45}$ and endocytosis ${ }^{46}$ using the post-Golgi recycling pathways. ${ }^{47}$ Interestingly, when SCAMP1 is silenced via siRNA, only then can the pancreatic cancer cells migrate freely in the lymph nodes. ${ }^{48}$ The other gene involved in chemotaxis and cell adhesion is the EPHB1, a tyrosine kinase receptor, that can activate MAPK and Jnk signaling cascades. ${ }^{49,50}$ Another gene that may contribute to the pathogensis of SLE is the Rho GTPase activating protein 25 (ARHGAP25). This protein is a GTPase activator for the Rho-type GTPases and is a negative regulator for phagocytosis in neutrophilic granulocytes. ${ }^{51}$

However, it should be noted that these LINE-1 chimeric transcripts have not been proven to exist in SLE neutrophils. We have merely searched the public database for any possible genes that may be affected by LINE-1 hypomethylation in the neutrophils from the SLE patients. Additional study is needed to investigate the functions of these genes to determine their contribution to the activity of the disease SLE.

On the other hand, the methylated levels and patterns for Alu, HERV-E and HERV-K in the neutrophils from the SLE patients were significantly not different when compared with the healthy controls. In contrast to $\mathrm{CD} 4{ }^{+} \mathrm{T}$ cells from active SLE patients, we have previously reported that there were significant differences of the methylated levels for HERV-E when compared with the inactive SLE patients. ${ }^{21}$ Therefore, it seems that the methylated levels for HERV are specific for a certain group of cells that may or may not contribute to the activity for the disease. 
Table 4 Functional annotation chart identified up- or down-regulated genes from the genes containing L1s group by the DAVID Functional Classification Tool

(a)

\begin{tabular}{|c|c|c|c|}
\hline Category & Phenotype function & P-value & LINE-1 downregulated gene in SLE neutrophils \\
\hline GOTERM_BP_FAT & Innate immune response & 0.014 & CD46, CR1, IL1RL2, LYST \\
\hline GOTERM_BP_FAT & Lymphocyte-mediated immunity & 0.028 & CD46, CR1, LYST \\
\hline GOTERM_BP_FAT & Leukocyte-mediated immunity & 0.04 & CD46, CR1, LYST \\
\hline
\end{tabular}

(b)

Category Phenotype function P-value LINE-1 upregulated gene in SLE neutrophils

GOTERM_BP_FAT GOTERM_BP_FAT GOTERM_BP_FAT GOTERM_BP_FAT GOTERM_BP_FAT GOTERM_BP_FAT GOTERM_BP_FAT GOTERM BP FAT GOTERM_BP_FAT

\section{Induction of apoptosis}

Induction of programmed cell death

Positive regulation for apoptosis

Positive regulation for programmed cell death

Positive regulation for cell death

Cellular calcium ion homeostasis

Elevation of cytosolic calcium ion concentration

Calcium ion homeostasis

Cytosolic calcium ion homeostasis
P-value

0.026

0.027

0.033

0.034

0.035

0.041

0.043

0.045

0.052
INE-1 upregulated gene in SLE neutrophils

AKAP13, CD38, GCH1, JAK2, C6, PTEN, VAV3 AKAP13, CD38, GCH1, JAK2, C6, PTEN, VAV3 AKAP13, CD38, GCH1, JAK2, C6, PTEN, STK3, VAV3 AKAP13, CD38, GCH1, JAK2, C6, PTEN, STK3, VAV3 AKAP13, CD38, GCH1, JAK2, C6, PTEN, STK3, VAV3 ATP7B, CD38, JAK2, CYSLTR1, PLCE1

CD38, JAK2, CYSLTR1, PLCE1

ATP7B, CD38, JAK2, CYSLTR1, PLCE1

CD38, JAK2, CYSLTR1, PLCE1

(c)

\begin{tabular}{|c|c|c|c|}
\hline Category & Phenotype function & P-value & LINE-1 downregulated gene in SLE neutrophils \\
\hline GOTERM_BP_FAT & Cytoskeleton-dependent intracellular transport & 0.067 & $D S T, M Y O 5 A$ \\
\hline GOTERM_BP_FAT & Macromolecule catabolic process & 0.082 & $F A F 1, G A N, P Y G B, P S M A 1$ \\
\hline
\end{tabular}

(d, e)

Category

Phenotype function

P-value

LINE-1 downregulated gene in SLE neutrophils

GOTERM_BP_FAT

Innate immune response

0.027

CD46, ILIRL2, LYST

GOTERM BP FAT

Sexual reproduction

0.051

CD46, FANCC, MICALCL, DNAH9

(f)

Category

Phenotype function

P-value

LINE-1 upregulated gene in SLE neutrophils

GOTERM BP FAT

Defense response

0.016

Regulation for the defense response to the virus by the host

ABCC9, CLEC5A, DDX58, GCH1, C6, ITGB1, IL15, PLD1

GOTERM_BP_FAT

GOTERM_BP_FAT

GOTERM_BP_FAT

GOTERM_BP_FAT

GOTERM_BP_FAT

GOTERM_BP_FAT

GOTERM BP FAT

Regulation for hydrolase activity

Response to zinc ion

Regulation for protein kinase B signaling cascade

Transmembrane receptor protein tyrosine kinase signaling pathway

Immune response

Hemostasis
0.038

0.056

0.07

0.07

0.071

0.074

0.078
$D D X 58, I L 15$

RABGAP1L, RICTOR, CHRM2, C6, PLCE1

ATP7B, PTEN

RICTOR, PTEN

EPHB1, EPS15, PTEN, PLCE1

OAS3, ABCC9, CLEC5A, DDX58, GCH1, C6, IL15

AP3B1, HMCN1, TFPI

$(\mathrm{g}, \mathrm{h})$

Category

Phenotype function

$\mathrm{P}$-value

LINE-1 upregulated gene in SLE neutrophils

GOTERM_BP_FAT

GOTERM_BP_FAT

GOTERM_BP_FAT

GOTERM_BP_FAT

GOTERM_BP_FAT

GOTERM_BP_FAT

GOTERM BP FAT

GOTERM_BP_FAT
Cell adhesion

Biological adhesion

Regulation for apoptosis

Regulation for programmed cell death

Regulation for cell death

Positive regulation for apoptosis

Positive regulation for programmed cell death

Positive regulation for cell death
0.0079

0.0079

0.066

0.067

0.068

0.09

0.091

0.092
DSCAM, COL4A6, COL24A1, CNTNAP5, FNDC3A

DSCAM, COL4A6, COL24A1, CNTNAP5, FNDC3A

AKAP13, STK3, TEX11, VAV3

AKAP13, STK3, TEX11, VAV3

AKAP13, STK3, TEX11, VAV3

AKAP13, STK3, VAV3

AKAP13, STK3, VAV3

AKAP13, STK3, VAV3

Abbreviations; DAVID, Database for Annotation, Visualization and Integrated Discovery; SLE, systemic lupus erythematosus.

(a) SLE downregulated genes with the genes containing L1s. (b) SLE upregulated genes with the genes containing L1s. (c) SLE downregulated genes with the genes containing sense L1s.

(d) There were no upregulated genes with the genes containing sense L1s. (e) SLE downregulated genes with the genes containing antisense L1s. (f) SLE upregulated genes with the genes

containing antisense L1s. (g) There were no downregulated genes with the genes containing both sense and antisense L1s. (h) SLE upregulated genes with the genes containing both sense and antisense Lls. 
Table 5 Chimeric transcripts extracted from the EST database of genes that have been reported to be differentially expressed in SLE neutrophils

\begin{tabular}{|c|c|c|c|c|c|}
\hline $\begin{array}{l}\text { Gene } \\
\text { symbol }\end{array}$ & Gene name & Function & $\begin{array}{l}\text { LINE-1 } \\
\text { orientation }\end{array}$ & $\begin{array}{l}\text { Expression } \\
\text { in } S L E^{\mathrm{a}}\end{array}$ & References \\
\hline$R A B G A P 1 L$ & $\begin{array}{l}\text { RAB GTPase activating protein 1-like } \\
\text { protein (RABGAP1L) }\end{array}$ & $\begin{array}{l}\text { A putative phosphotyrosine binding (PTB) domain expressed in } \\
\text { megakaryocytes }\end{array}$ & Antisense & Upregulated & 43,44 \\
\hline SCAMP1 & Secretory carrier membrane protein 1 & $\begin{array}{l}\text { Involved in exocytosis and endocytosis through post-Golgi } \\
\text { recycling pathways }\end{array}$ & Antisense & Upregulated & $45-48$ \\
\hline SSBP2 & Single-stranded DNA binding protein 2 & $\begin{array}{l}\text { Growth arrest activity in myeloid leukemia cells, indicating its } \\
\text { function in tumor suppression }\end{array}$ & Antisense & Upregulated & 52 \\
\hline DCTN4 & Dynactin 4 & $\begin{array}{l}\text { Interacted with ATP7B, a liver protein required to regulate and } \\
\text { maintain copper homeostasis }\end{array}$ & Antisense & Upregulated & 53 \\
\hline$E P H B 1$ & $E P H$ receptor $B 1$ & $\begin{array}{l}\text { Activate MAPK and Jnk signaling cascades, leading to } \\
\text { chemotaxis and cell adhesion, respectively }\end{array}$ & Antisense & Upregulated & 49,50 \\
\hline SLCO1A2 & $\begin{array}{l}\text { Solute carrier organic anion transporter } \\
\text { family member } 1 A 2\end{array}$ & A sodium-independent transporter involved in drug deposition & Antisense & Downregulated & 54 \\
\hline ARHGAP25 & Rho GTPase activating protein 25 & A negative regulator of phagocytosis in neutrophilic granulocytes & Sense & Downregulated & 51 \\
\hline COL24A1 & Collagen, type XXIV, alpha 1 & May participate in bone development & $\begin{array}{l}\text { Both sense and } \\
\text { antisense }\end{array}$ & Upregulated & 55 \\
\hline C12orf4 & Chromosome 12 open reading frame 4 & Uncharacterized protein C12orf4 & Antisense & Upregulated & \\
\hline
\end{tabular}

Abbreviations: EST, expressed sequence tag; SLE, systemic lupus erythematosus.

a Gene expression profile obtained from SLE neutrophil microarray data from the GEO data set GSE27427 (see Barrett et al. ${ }^{35}$ ).

In conclusion, the neutrophils from the SLE patients had DNA hypomethylation at specific IRSs for LINE-1 but not Alu, HERV-E and HERV-K. According to bioinformatics analysis from the gene expressions in SLE neutrophils compared with the pattern of intragenic LINE-1, hypomethylated LINE-1 may have an effect in cis to upregulate some cell death process genes. Additional study is needed to ascertain the functional role of these IRSs in neutrophils during hypomethylation because it may lead to the discovery of a novel pathway for the pathogenesis of SLE.

\section{ACKNOWLEDGEMENTS}

This study was supported by the National Center for Genetic Engineering and Biotechnology (BIOTEC) (RES_56_044_30_005), Thailand. PS was supported by the Postdoctoral Fellowship from the Chulalongkorn University. YA and $\mathrm{NH}$ were supported by the Center of Excellence in Immunology and Immune Mediated Diseases, Chulalongkorn University. AM was supported by the Research Chair Grant 2011, National Science and Technology Development Agency (NSTDA), Thailand, and the Four Seasons Hotel Bangkok's 4th Cancer Care charity fun run in coordination with the Thai Red Cross Society and Center of Excellence in Molecular Genetics of Cancer and Human Diseases, Chulalongkorn University.

1 Javierre, B. M., Fernandez, A. F., Richter, J., Al-Shahrour, F., Martin-Subero, J. I., Rodriguez-Ubreva, J. et al. Changes in the pattern of DNA methylation associate with twin discordance in systemic lupus erythematosus. Genome Res. 20, 170-179 (2010).

2 Liu, C. C., Ou, T. T., Wu, C. C., Li, R. N., Lin, Y. C., Lin, C. H. et al. Global DNA methylation, DNMT1, and MBD2 in patients with systemic lupus erythematosus. Lupus 20, 131-136 (2011).

3 Luo, Y., Li, Y., Su, Y., Yin, H., Hu, N., Wang, S. et al. Abnormal DNA methylation in T cells from patients with subacute cutaneous lupus erythematosus. Br. J. Dermatol. 159, 827-833 (2008).

4 Lei, W., Luo, Y., Lei, W., Luo, Y., Yan, K., Zhao, S. et al. Abnormal DNA methylation in CD4 + T cells from patients with systemic lupus erythematosus, systemic sclerosis, and dermatomyositis. Scand. J. Rheumatol. 38, 369-374 (2009).

5 Absher, D. M., Li, X., Waite, L. L., Gibson, A., Roberts, K., Edberg, J. et al. Genomewide DNA methylation analysis of systemic lupus erythematosus reveals persistent hypomethylation of interferon genes and compositional changes to CD4 + T-cell populations. PLoS Genet. 9, e1003678 (2013).
6 Coit, P., Jeffries, M., Altorok, N., Dozmorov, M. G., Koelsch, K. A., Wren, J. D. et al. Genome-wide DNA methylation study suggests epigenetic accessibility and transcriptional poising of interferon-regulated genes in naive CD4 + T cells from lupus patients. J. Autoimmun. 43, 78-84 (2013).

7 Quddus, J., Johnson, K. J., Gavalchin, J., Amento, E. P., Chrisp, C. E., Yung, R. L. et al. Treating activated CD4 + T cells with either of two distinct DNA methyltransferase inhibitors, 5-azacytidine or procainamide, is sufficient to cause a lupus-like disease in syngeneic mice. J. Clin. Invest. 92, 38-53 (1993).

8 Levy, S., Sutton, G., Ng, P. C., Feuk, L., Halpern, A. L., Walenz, B. P. et al. The diploid genome sequence of an individual human. PLoS Biol. 5, e254 (2007).

9 Chalitchagorn, K., Shuangshoti, S., Hourpai, N., Kongruttanachok, N., Tangkijvanich, P., Thong-ngam, D. et al. Distinctive pattern of LINE-1 methylation level in normal tissues and the association with carcinogenesis. Oncogene 23, 8841-8846 (2004).

10 Kremenskoy, M., Kremenska, Y., Ohgane, J., Hattori, N., Tanaka, S., Hashizume, K. et al. Genome-wide analysis of DNA methylation status of CpG islands in embryoid bodies, teratomas, and fetuses. Biochem. Biophys. Res. Commun. 311, 884-890 (2003).

11 Jintaridth, P. \& Mutirangura, A. Distinctive patterns of age-dependent hypomethylation in interspersed repetitive sequences. Physiol. Genomics. 41, 194-200 (2010).

12 Wang, L., Wang, F., Guan, J., Le, J., Wu, L., Zou, J. et al. Relation between hypomethylation of long interspersed nucleotide elements and risk of neural tube defects. Am. J. Clin. Nutr. 91, 1359-1367 (2010).

13 Tajuddin, S. M., Amaral, A. F., Fernandez, A. F., Rodriguez-Rodero, S., Rodriguez, R. M., Moore, L. E. et al. Genetic and non-genetic predictors of LINE-1 methylation in leukocyte DNA. Environ. Health. Perspect. 121, 650-656 (2013)

14 Brunaud, L., Alberto, J. M., Ayav, A., Gerard, P., Namour, F., Antunes, L. et al. Effects of vitamin B12 and folate deficiencies on DNA methylation and carcinogenesis in rat liver. Clin. Chem. Lab. Med. 41, 1012-1019 (2003).

15 Kitkumthorn, N. \& Mutirangura, A. Long interspersed nuclear element-1 hypomethylation in cancer: biology and clinical applications. Clin. Epigenet. 2, 315-330 (2011).

16 Nakkuntod, J., Avihingsanon, Y., Mutirangura, A. \& Hirankarn, N. Hypomethylation of LINE-1 but not Alu in lymphocyte subsets of systemic lupus erythematosus patients. Clin. Chim. Acta 412, 1457-1461 (2011).

17 Karouzakis, E., Gay, R. E., Michel, B. A., Gay, S. \& Neidhart, M. DNA hypomethylation in rheumatoid arthritis synovial fibroblasts. Arthritis Rheum. 60, 3613-3622 (2009).

18 Okada, M., Ogasawara, H., Kaneko, H., Hishikawa, T., Sekigawa, I., Hashimoto, H. et al. Role of DNA methylation in transcription of human endogenous retrovirus in the pathogenesis of systemic lupus erythematosus. J. Rheumatol. 29, 1678-1682 (2002).

19 Piotrowski, P. C., Duriagin, S. \& Jagodzinski, P. P. Expression of human endogenous retrovirus clone 4-1 may correlate with blood plasma concentration of anti-U1 RNP and anti-Sm nuclear antibodies. Clin. Rheumatol. 24, 620-624 (2005).

20 Ejtehadi, H. D., Freimanis, G. L., Ali, H. A., Bowman, S., Alavi, A., Axford, J. et al. The potential role of human endogenous retrovirus $\mathrm{K} 10$ in the pathogenesis of rheumatoid arthritis: a preliminary study. Ann. Rheum. Dis. 65, 612-616 (2006).

21 Nakkuntod, J., Sukkapan, P., Avihingsanon, Y., Mutirangura, A. \& Hirankarn, N. DNA methylation of human endogenous retrovirus in systemic lupus erythematosus. J. Hum. Genet. 58, 241-249 (2013). 
22 Wright, H. L., Moots, R. J., Bucknall, R. C. \& Edwards, S. W. Neutrophil function in inflammation and inflammatory diseases. Rheumatology (Oxford, England) 49, 1618-1631 (2010).

23 Craft, J. E. Dissecting the immune cell mayhem that drives lupus pathogenesis. Sci. Transl. Med. 3, 73 ps79 (2011).

24 Reinius, L. E., Acevedo, N., Joerink, M., Pershagen, G., Dahlen, S. E., Greco, D. et al. Differential DNA methylation in purified human blood cells: implications for cell lineage and studies on disease susceptibility. PLoS One 7, e41361 (2012).

25 Wu, H. C., Delgado-Cruzata, L., Flom, J. D., Kappil, M., Ferris, J. S., Liao, Y. et al. Global methylation profiles in DNA from different blood cell types. Epigenetics 6, 76-85 (2011)

26 Gladman, D. D., Ibanez, D. \& Urowitz, M. B. Systemic lupus erythematosus disease activity index 2000. J. Rheumatol. 29, 288-291 (2002).

27 Miller, S. A., Dykes, D. D. \& Polesky, H. F. A simple salting out procedure for extracting DNA from human nucleated cells. Nucleic Acids Res. 16, 1215 (1988).

28 Pobsook, T., Subbalekha, K., Sannikorn, P. \& Mutirangura, A. Improved measurement of LINE-1 sequence methylation for cancer detection. Clin. Chim. Acta. 412, 314-321 (2011).

29 Sirivanichsuntorn, P., Keelawat, S., Danuthai, K., Mutirangura, A., Subbalekha, K. \& Kitkumthorn, N. LINE-1 and Alu hypomethylation in mucoepidermoid carcinoma. BMC Clin. Pathol. 13, 10 (2013).

30 Kitkumthorn, N., Tuangsintanakul, T., Rattanatanyong, P., Tiwawech, D. \& Mutirangura, A. LINE-1 methylation in the peripheral blood mononuclear cells of cancer patients. Clin. Chim. Acta 413, 869-874 (2012).

31 Aporntewan, C., Phokaew, C., Piriyapongsa, J., Ngamphiw, C., Ittiwut, C., Tongsima, S. et al. Hypomethylation of intragenic LINE-1 represses transcription in cancer cells through AG02. PLoS One 6, e17934 (2011).

32 Aporntewan, C. \& Mutirangura, A. Connection up- and down-regulation expression analysis of microarrays (CU-DREAM): a physiogenomic discovery tool. Asian Biomed. 5, 257-262 (2011)

33 Penzkofer, T., Dandekar, T. \& Zemojtel, T. L1Base: from functional annotation to prediction of active LINE-1 elements. Nucleic Acids Res. 33, D498-D500 (2005).

34 Edgar, R., Domrachev, M. \& Lash, A. E. Gene Expression Omnibus: NCBI gene expression and hybridization array data repository. Nucleic Acids Res. 30, 207-210 (2002).

35 Barrett, T., Troup, D. B., Wilhite, S. E., Ledoux, P., Rudnev, D., Evangelista, C. et al NCBI GEO: archive for high-throughput functional genomic data. Nucleic Acids Res. 37, D885-D890 (2009).

36 Garcia-Romo, G. S., Caielli, S., Vega, B., Connolly, J., Allantaz, F., Xu, Z. et al. Netting neutrophils are major inducers of type I IFN production in pediatric systemic lupus erythematosus. Sci. Transl. Med. 3, 73ra20 (2011).

37 Huang da, W., Sherman, B. T. \& Lempicki, R. A. Systematic and integrative analysis of large gene lists using DAVID bioinformatics resources. Nat. Protoc. 4, 44-57 (2009).

38 Huang da, W., Sherman, B. T., Tan, Q., Collins, J. R., Alvord, W. G., Roayaei, J. et al. The DAVID Gene Functional Classification Tool: a novel biological module-centric algorithm to functionally analyze large gene lists. Genome. Biol. 8, R183 (2007).
39 Oikonomopoulou, K., Ricklin, D., Ward, P. A. \& Lambris, J. D. Interactions between coagulation and complement-their role in inflammation. Semin. Immunopathol. 34 151-165 (2012).

40 Matlik, K., Redik, K. \& Speek, M. L1 antisense promoter drives tissue-specific transcription of human genes. J. Biomed. Biotechnol. 2006, 71753 (2006).

41 Speek, M. Antisense promoter of human L1 retrotransposon drives transcription of adjacent cellular genes. Mol. Cell Biol. 21, 1973-1985 (2001).

42 Renaudineau, Y., Vallet, S., Le Dantec, C., Hillion, S., Saraux, A. \& Youinou, P. Characterization of the human CD5 endogenous retrovirus-E in B lymphocytes. Genes Immun. 6, 663-671 (2005).

43 Hidaka, M., Caruana, G., Stanford, W. L., Sam, M., Correll, P. H. \& Bernstein, A. Gene trapping of two novel genes, $\mathrm{Hzf}$ and $\mathrm{Hhl}$, expressed in hematopoietic cells. Mech. Dev. 90, 3-15 (2000).

44 Kim, J. H., Jung, S. H., Bae, J. S., Lee, H. S., Yim, S. H., Park, S. Y. et al. Deletion variants of RABGAP1L, 10q21.3, and C4 are associated with the risk of systemic lupus erythematosus in Korean women. Arthritis Rheum. 65, 1055-1063 (2013).

45 Zhang, J. \& Castle, D. Regulation of fusion pore closure and compound exocytosis in neuroendocrine PC12 cells by SCAMP1. Traffic 12, 600-614 (2011).

46 Fernandez-Chacon, R., Achiriloaie, M., Janz, R., Albanesi, J. P. \& Sudhof, T. C. SCAMP1 function in endocytosis. J. Biol. Chem. 275, 12752-12756 (2000).

47 Lin, P. J., Williams, W. P., Luu, Y., Molday, R. S., Orlowski, J. \& Numata, M. Secretory carrier membrane proteins interact and regulate trafficking of the organellar $(\mathrm{Na}+$, $\mathrm{K}+\mathrm{)} / \mathrm{H}+$ exchanger NHE7. J. Cell Sci. 118, 1885-1897 (2005).

48 Yang, S., Lee, K. T., Lee, J. Y., Lee, J. K., Lee, K. H. \& Rhee, J. C. Inhibition of SCAMP1 suppresses cell migration and invasion in human pancreatic and gallbladder cancer cells. Tumour Biol. 34, 2731-2739 (2013).

49 Vindis, C., Cerretti, D. P., Daniel, T. O. \& Huynh-Do, U. EphB1 recruits c-Src and p52Shc to activate MAPK/ERK and promote chemotaxis. J. Cell Biol. 162, 661-671 (2003).

50 Becker, E., Huynh-Do, U., Holland, S., Pawson, T., Daniel, T. O. \& Skolnik, E. Y. Nck interacting Ste20 kinase couples Eph receptors to C-Jun N-terminal kinase and integrin activation. Mol. Cell Biol. 20, 1537-1545 (2000).

51 Csepanyi-Komi, R., Sirokmany, G., Geiszt, M. \& Ligeti, E. ARHGAP25, a novel Rac GTPase-activating protein, regulates phagocytosis in human neutrophilic granulocytes. Blood 119, 573-582 (2012).

52 Liang, H., Samanta, S. \& Nagarajan, L. SSBP2, a candidate tumor suppressor gene induces growth arrest and differentiation of myeloid leukemia cells. Oncogene 24 2625-2634 (2005).

53 Lim, C. M., Cater, M. A., Mercer, J. F. \& La Fontaine, S. Copper-dependent interaction of dynactin subunit p62 with the N terminus of ATP7B but not ATP7A. J. Biol. Chem 281, 14006-14014 (2006).

54 Yamakawa, Y., Hamada, A., Shuto, T., Yuki, M., Uchida, T., Kai, H. et al. Pharmacokinetic impact of SLCO1A2 polymorphisms on imatinib disposition in patients with chronic myeloid leukemia. Clin. Pharmacol. Ther. 90, 157-163 (2011)

55 Matsuo, N., Tanaka, S., Gordon, M. K. Koch, M. Yoshioka, H. \& Ramirez, F. CREBAP1 protein complexes regulate transcription of the collagen XXIV gene (Col24a1) in osteoblasts. J. Biol. Chem. 281, 5445-5452 (2006).

Supplementary Information accompanies the paper on Journal of Human Genetics website (http://www.nature.com/jhg) 